\title{
NaPontaDaLíngua: Um Aplicativo para Apoiar o Processo de Ensino-Aprendizagem da Língua Portuguesa
}

\author{
Wagner Gaspar ${ }^{1}$, Elaine H. T. Oliveira ${ }^{2}$, Davidson Cury ${ }^{1}$ \\ ${ }^{1}$ Departamento de Informática - Universidade Federal do Espírito Santo (UFES) \\ CEP 29.075-910 - Vitória - ES - Brasil \\ ${ }^{2}$ Instituto de Computação - Universidade Federal do Amazonas (UFAM) \\ CEP 69.077-000 - Manaus - AM - Brasil \\ $\{$ wg, elaine\}@icomp.ufam.edu.br, dede@inf.ufes.br
}

\begin{abstract}
Learning the written form of a language is a long and complex task. Several factors can make the learning process more difficult, such as the fact that some sounds be represented in different ways in the Portuguese language, like the /Z/ sound, represented by s in "casa", $z$ in "beleza" and $x$ in "exame". In an attempt to mitigate these difficulties we developed NaPontaDaLingua, a free application that aims to help students address these peculiarities of the Portuguese language in a playful way, working with the origin of words. Student can interact with the application in different ways and can test their knowledge in the game mode.

Resumo: A aprendizagem da língua escrita é uma tarefa longa e complexa. Muitos fatores podem tornar o processo de aprendizagem mais dificil, como o fato de um mesmo som ser grafado de diferentes formas na Língua Portuguesa (LP), como o som /Z/ grafado com s em "casa", com z em "beleza" ou com $x$ em "exame". Na tentativa de amenizar estas dificuldades, foi desenvolvido o aplicativo NaPontaDaLingua, uma ferramenta gratuita que visa ajudar os estudantes a abordar essa dificuldade de forma mais divertida, trabalhando com a origem das palavras. $O$ estudante pode interagir com o aplicativo de diversas formas e ainda testar seus conhecimentos no modo jogo.
\end{abstract}

\section{Introdução}

Segundo [Santos et al. 2009] a compreensão da natureza do sistema da escrita alfabética exige do aprendiz um grande esforço cognitivo, uma vez que a aprendizagem da língua escrita é uma tarefa longa, complexa e dependente de vários fatores. Assim, normas ortográficas têm sido criadas na tentativa de unificar e tornar a língua escrita acessível a todos [Santos et al. 2009; Zanella 2010].

Uma grande dificuldade na LP, apresentada em [Romanelli e Guimarães 2009; Santos et al. 2009] é o fato de um mesmo som ser grafado de diferentes formas, como por exemplo, o som /Z/ que pode ser grafado com s em “casa”, com z em "beleza” ou com x em "exame". Segundo algumas pesquisas apresentadas em [Santos et al. 2009] com turmas de $5^{\mathrm{a}}$ a $8^{\mathrm{a}}$ séries, o erro por substituição de letras foi o que mais se manteve ao longo do tempo. 
V Congresso Brasileiro de Informática na Educação (CBIE 2016)

Anais do XXVII Simpósio Brasileiro de Informática na Educação (SBIE 2016)

Os métodos de ensino têm evoluído e incorporado as tecnologias [Marques e Silva 2012] que, juntamente com o avanço e popularização das Tecnologias Digitais da Informação Comunicação (TDICs) têm possibilitado o surgimento de aplicações mobile learning (m-learning) nas mais diversas áreas do conhecimento, dentre as quais na LP.

Com base nessas informações e especialmente direcionado pelos resultados apresentados em [Gaspar et al. 2015], é apresentado aqui a proposta do aplicativo NaPontaDaLínga seguido de uma inspeção de usabilidade. O aplicativo objetiva ajudar o estudante a abordar essas dificuldades da LP de forma mais lúdica. O estudante pode interagir com o aplicativo de diversas formas e ainda testar seus conhecimentos no modo jogo, conhecendo a origem das palavras, além de uma seção com alguns dos erros mais comuns no uso da LP.

Este trabalho está dividido nas seguintes seções além desta introdução. Na seção 2 são apresentados os trabalhos relacionados. Na seção 3 é apresentada a metodologia, assim como o aplicativo e as etapas do desenvolvimento. Na seção 4 são apresentados os resultados da inspeção de usabilidade. As conclusões e trabalhos futuros são apresentados na seção 5 .

\section{Trabalhos Relacionados}

Há na literatura diversos trabalhos propondo aplicações m-learning e avaliação de seu impacto na aprendizagem do estudante nas diversas áreas do conhecimento [Luz e Fonseca 2013; Silva et al. 2014]. São apresentados a seguir alguns exemplos cujo objetivo é auxiliar no ensino-aprendizagem da LP.

Em [Marques e Silva 2012] foi proposto o jogo OrtograFixe, desenvolvido para a plataforma Android. Tem como público alvo os estudantes do ensino fundamental e médio. Seu objetivo é motivar o estudante a escrever corretamente, aprendendo as regras do novo acordo ortográfico que entrou em vigor no mesmo ano.

Sua utilização é simples, apresenta ao estudante uma regra, em seguida é apresentado um conjunto de palavras ao passo que o estudante tem 20 segundos para identificar quais palavras pertencem à regra apresentada. Decorrido este tempo, uma nova regra é apresentada. Caso o estudante erre, uma mensagem com a referida regra é exibida. Os autores apontam como trabalho futuro a validação das funcionalidades com profissionais da área de educação e estudantes do ensino fundamental e médio.

O AlfabetoKinect, proposto em [Alves et al. 2012], faz uso do Kinect para mapear tridimensionalmente a posição do usuário no ambiente. Foi idealizado para auxiliar na alfabetização de crianças. Seus três componentes principais são: uma letra, uma palavra e uma imagem, cada qual dentro de uma forma geométrica diferente.

Estes componentes devem ser arrastados do lado esquerdo para a sua respectiva posição no lado direito da tela. Este movimento de arrastar é feito pelo estudante como se ele estivesse movendo algo no mundo real, o movimento é capturado pelo Kinect e codificado para o mundo virtual.

A proposta foi apresentada a cinco profissionais da área entre mestres e doutores e todos concordaram que é atrativa e estimula a curiosidade dos estudantes. Sugestões de melhorias na interface e criação de níveis similares aos de jogos foram feitas. 
V Congresso Brasileiro de Informática na Educação (CBIE 2016)

Anais do XXVII Simpósio Brasileiro de Informática na Educação (SBIE 2016)

Por fim, o JOE (Jogo Ortográfico Educacional) proposto em [Paschoal et al. 2014], desenvolvido para a plataforma Android, aborda predominantemente a acentuação e o uso do hífen através de dois modos: treino e desafio.

Ao iniciar, o estudante ouve uma palavra e deve escrevê-la, em seguida clicar no botão "Verificar Palavra". Neste momento a regra que classifica a palavra é exibida (somente no modo treino) e a pontuação é somada aos acertos ou aos erros. É apresentada como trabalho futuro a condução de experimentos com estudantes dos níveis médio, técnico e de graduação.

São apresentadas na Tabela 1 as principais características desses aplicativos, como o público alvo a que se destinam, o conteúdo que abordam, e suas possíveis formas de utilização.

Tabela 1. Principais características dos aplicativos apresentados

\begin{tabular}{|l|l|l|l|}
\hline & \multicolumn{1}{|c|}{ Público alvo } & \multicolumn{1}{c|}{ Conteúdo } & \multicolumn{1}{c|}{ Interação } \\
\hline Ortografixe & Ensino fundamental e médio & $\begin{array}{l}\text { Regras no novo acordo } \\
\text { ortográfico }\end{array}$ & Jogo \\
\hline AlfabetoKinect & Crianças em alfabetização & Letras, palavras e imagens & Jogo \\
\hline JOE & Níveis médio, técnico e superior & Acentuação e hífen & Treino e desafio \\
\hline
\end{tabular}

Ainda abordando a aprendizagem da LP, em [Tavares et al. 2014] é apresentado o SensorLibras que, fazendo uso de um dispositivo Sun SPOT, possibilita o ensino da LP para surdos brasileiros. O estudante usa uma espécie de "luva" com sensores que capturam os movimentos e os transmitem para uma estação-base que processa estes sinais e os converte em letras do alfabeto.

Em [Lopes 2014] é apresentado uma proposta de material digital interativo para tablet, trabalhando com a LP através de textos, imagens, infográficos, vídeos, charges, dentre outros. Um protótipo é apresentado para elucidar a abrangência da proposta.

Nenhuma das propostas abordou a ortografia de forma mais ampla, especialmente os casos que dependem de memorização, e apresentam apenas uma forma de utilização. Mesmo o JOE com os modos treino e desafio, pode ser considerado apenas um, pois a única diferença entre eles está na contagem dos pontos e exibição da regra ortográfica no modo treino, mas sua execução é igual. Assim, buscou-se nesta proposta trabalhar a parte ortográfica e ainda permitir diferentes interações com o aplicativo.

\subsection{O Mapeamento Sistemático da Literatura}

Ao iniciar o estudo de um domínio com poucas evidências ou cujo tema seja muito amplo, realizar um MSL pode ser muito útil. Este tem a finalidade de fornecer uma visão geral da área de investigação, classificando e identificando toda investigação relacionada a um amplo tema [Kitchenham et al. 2011; Petersen et al. 2008].

Com a realização de um MSL, foi possível confirmar a idéia inicial da existência de poucas publicações relacionando o uso dos dispositivos móveis com o ensinoaprendizagem da LP. Ao final deste, apenas nove publicações atendiam aos critérios de inclusão estabelecidos, dos quais apenas quatro propunham uma aplicação para esta finalidade. 
De forma geral, os trabalhos apresentaram boas propostas para esta área ainda carente, com bons resultados, assim como foi constatada boa receptividade por parte dos estudantes. Foram utilizadas tecnologias como sensores para captura de movimentos, tablet com tela capacitiva, e-mail, chat, kinect, kit sun spot e o serviço de mensagens curtas (Short Message Service - SMS). Foram abordados assuntos como acentuação e hífen, formação de palavras e ortografia, e ainda alfabetização, produção de texto, precisão vocabular, construção frasal, correção gramatical, concordância verbal e nominal, regência, crase, pronomes, pontuação e flexão verbal e nominal com o auxilio de um Ambiente Virtual de Aprendizagem (AVA).

Em contrapartida, deixou evidente que muito ainda há a ser feito para tornar o m-learning uma realidade mais presente na vida dos estudantes. As possibilidades incorporadas pelos dispositivos móveis, especialmente smartphones e tablets, foram pouco exploradas, não aproveitando o grande potencial de inovação inerente nesses aparelhos. Informações mais detalhadas referentes a este mapeamento e seus resultados podem ser encontradas em [Gaspar et al. 2015].

\section{Metodologia e Desenvolvimento do NaPontaDaLíngua}

São apresentadas nessa seção as etapas que constituíram todo o processo de elaboração e desenvolvimento do aplicativo, assim como as decisões e as tecnologias utilizadas.

\subsection{Arquitetura}

O estudante será o principal ator, interagindo com seu dispositivo móvel. A utilização das funcionalidades do aplicativo não deverá depender de acesso a internet, permitindo assim sua utilização em qualquer lugar a qualquer momento. Numa possível necessidade de acesso a internet, como na criação de uma conta, por exemplo, esta função não deverá bloquear a utilização dos demais recursos do aplicativo.

\subsection{Recursos do aplicativo}

A proposta do aplicativo foi elaborada de tal forma que proporcionasse ao estudante diferentes visualizações da mesma informação. São apresentados a seguir os quatro principais recursos do aplicativo.

\subsubsection{Treino}

Nesta opção, o estudante pode testar seus conhecimentos de ortografia. Ao acessá-la, uma palavra é selecionada aleatoriamente dentre as palavras cadastradas no aplicativo. Esta é exibida ao estudante juntamente com outras três variações (grafadas de forma errada), o estudante deve escolher a palavra que julgar estar correta, clicando sobre ela.

Ao clicar em uma das quatro opções, é informado ao estudante se ele acertou. A palavra grafada corretamente é apresentada juntamente com um breve texto contendo sua origem. Ao clicar no botão "Continuar", uma nova palavra é selecionada e o processo recomeça, até que o estudante decida parar.

\subsubsection{Dicionário}

Esta função pode ser utilizada pelo estudante para uma consulta rápida a uma determinada palavra. Ao acessá-la, uma lista contendo todas as palavras cadastradas no aplicativo é apresentada. 
V Congresso Brasileiro de Informática na Educação (CBIE 2016)

Anais do XXVII Simpósio Brasileiro de Informática na Educação (SBIE 2016)

Ao clicar sobre uma das palavras, são apresentadas ao estudante as informações de origem daquela palavra, a mesma informação apresentada no modo de treino, porém sem a informação de erro ou acerto, uma vez que o estudante está apenas consultando uma palavra e não treinando.

\subsubsection{Grafo}

Através deste recurso o estudante pode encontrar todas as línguas cadastradas no aplicativo que contribuíram para a formação da LP, assim como as palavras originárias de uma mesma língua. Ao acessar a função, são apresentados ao estudante vários balões, cada um representando uma língua diferente. Cada balão possui uma linha ligando-o a um balão central que representa a LP.

Caso deseje, o estudante pode arrastar os balões permitindo uma arrumação visual mais adequada, ou ainda clicar sobre o balão de uma língua específica. Ao clicar sobre um dos balões, serão apresentadas todas as palavras cadastradas originárias daquela língua. Tendo escolhido uma língua, clicado sobre ela, e visualizado as palavras originárias da mesma, o estudante pode ainda ter acesso às informações de cada palavra clicando sobre seu respectivo balão.

\subsubsection{Jogo}

Esta funcionalidade permite ao estudante testar seus conhecimentos em ortografia de forma mais lúdica. Pontos são contabilizados e ao final o estudante tem acesso a uma lista contendo todas as palavras que ele errou durante o jogo.

Sua utilização é bem simples. Mantendo a ideia dos balões, cada um possui uma palavra em seu interior que pode estar grafada corretamente ou não. Estes balões aparecem em um lado da tela e vão se movendo até o outro lado, o estudante deve reconhecer as palavras grafadas corretamente e estourar seus balões.

\subsection{Desenvolvimento}

Sua arquitetura foi pensada para que o estudante pudesse utilizá-lo em qualquer lugar, de forma que os recursos dependentes de internet não impossibilitassem sua utilização, como mostrado na Figura 1.

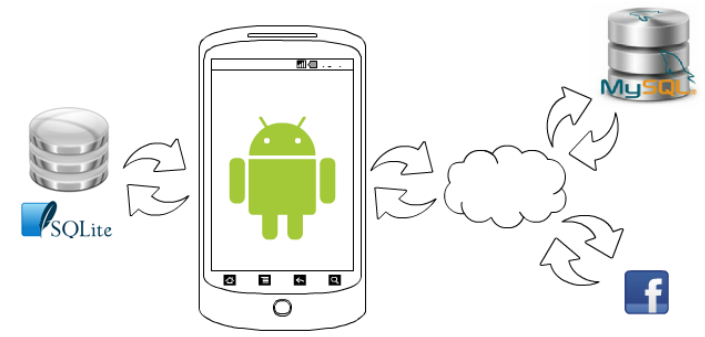

Figura 1. Arquitetura do aplicativo NaPontaDaLíngua

Foi escolhida a plataforma Android versão 4.0, por ser aberta e amplamente utilizada. Todas as informações são armazenadas no SQLite, o Sistema Gerenciador de Banco de Dados (SGBD) do Android, dispensando assim a necessidade de acesso à internet. Esta só é necessária caso o usuário queira inserir um comentário, criando uma conta ou podendo acessar com o Facebook. Os comentários são armazenados em um servidor web desenvolvido para este propósito, fazendo uso do SGBD MySql. 
V Congresso Brasileiro de Informática na Educação (CBIE 2016)

Anais do XXVII Simpósio Brasileiro de Informática na Educação (SBIE 2016)

Antes do desenvolvimento, um protótipo foi elaborado na ferramenta Pencil versão 2.0.5. Nesta, é possível não apenas a elaboração das telas como também criar links entre elas, permitindo assim simular o comportamento do aplicativo ao clicar nos botões. A implementação foi realizada na IDE Android Studio versão 1.0.

$\mathrm{Na}$ primeira tela, apresentada na Figura 2a, o estudante tem acesso a todas as funcionalidades disponíveis, os módulos treino, dicionário, grafo e ao jogo. Nesta tela ele também pode criar sua conta ou acessar com o Facebook, para isso é necessário que esteja conectado à internet. Ainda é possível consultar uma lista de erros comuns no uso da LP, clicando no botão com uma interrogação no canto superior direito.

Ao clicar em "Treinar", uma palavra é selecionada aleatoriamente para compor a tela apresentada na Figura 2b. Quatro opções da mesma palavra são apresentadas, porém apenas uma está correta. $\mathrm{O}$ estudante deve clicar sobre a palavra que julga estar correta. Feito isso, será exibida a tela da Figura 2c, informando se o estudante acertou ou não, a grafia correta da palavra, sua origem, e três botões adicionais.

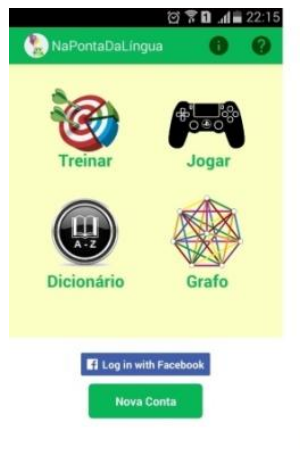

(a)

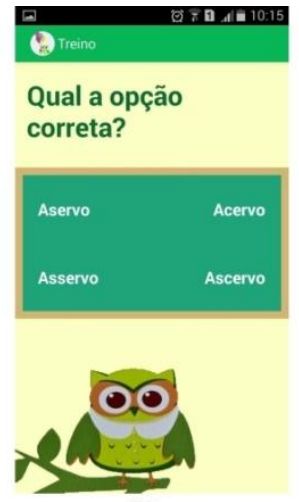

(b)

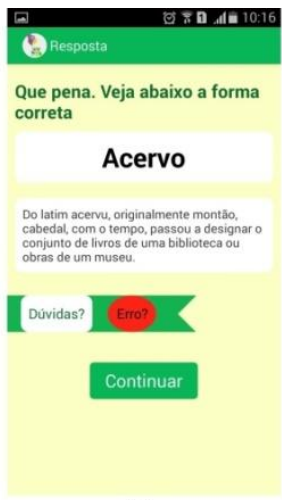

(c)

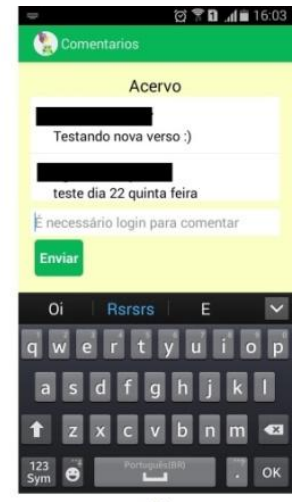

(d)

Figura 2. Telas inicial e do modo treino

No botão "Dúvida?" o estudante pode postar um comentário, como mostrado na Figura 2d. O botão "Erro?" permite informar aos desenvolvedores algum erro no conteúdo da tela. Estas funções requerem acesso à internet e login por parte do estudante. Por fim o botão "Continuar" irá sortear uma nova palavra e conduzir o estudante à tela da Figura 2b, dando continuidade ao treino.

Ao acessar a função Grafo, será exibida a tela da Figura 3a. Esta apresenta todas as línguas (cadastradas no aplicativo) que contribuíram para a formação da LP.

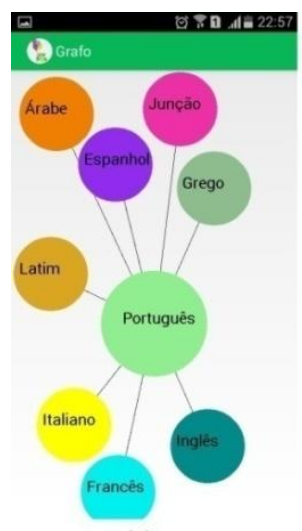

(a)

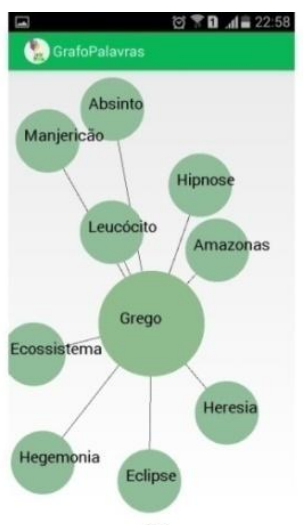

(b)

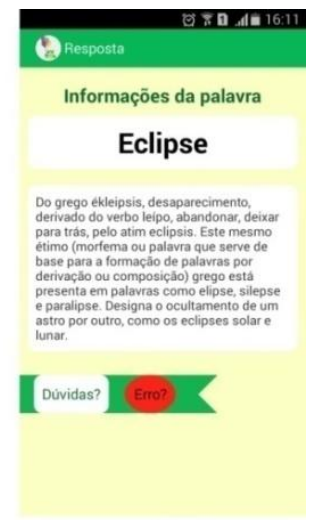

(c)

Figura 3. Função grafo 
V Congresso Brasileiro de Informática na Educação (CBIE 2016)

Anais do XXVII Simpósio Brasileiro de Informática na Educação (SBIE 2016)

Caso o estudante queira consultar as palavras herdadas de uma mesma língua, do grego por exemplo, basta clicar no balão "Grego", sendo conduzido à tela mostrada na Figura 3b. Nesta são apresentadas todas as palavras (cadastradas no aplicativo) herdadas da língua grega, bastando clicar sobre uma delas para ter acesso à informação completa como mostrada na Figura 3c. O estudante também pode comentar e reportar algum erro.

Outra funcionalidade disponível é o modo Jogo, mostrado na Figura 4. Na primeira tela, Figura 4a, o estudante tem uma breve explicação do jogo, que consiste em estourar os balões cuja palavra esteja correta. A cada palavra certa ele ganha cinco pontos, a cada palavra errada ele perde cinco pontos e, caso um balão com uma palavra correta suma da tela sem que o estudante o identifique, ele perde três pontos.

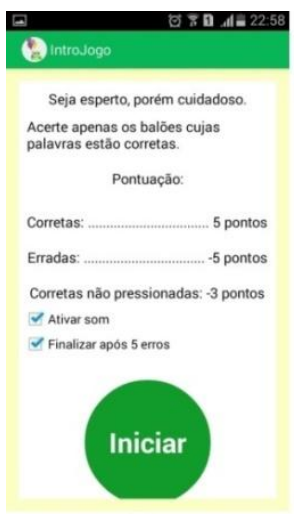

(a)

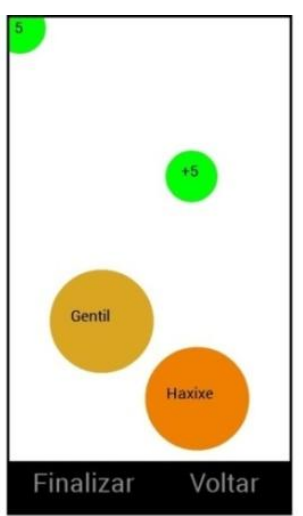

(b)

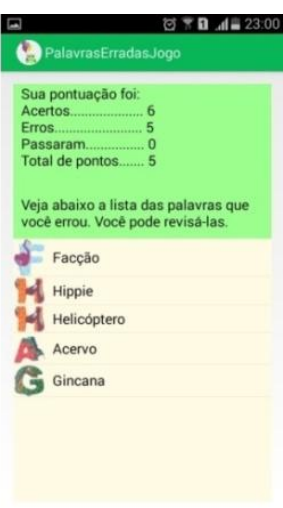

(c)

Figura 4. Função jogo

Nesta tela o estudante também pode desativar o som e a contagem de erros. Ao clicar no botão "Iniciar", dá-se início ao jogo como mostrado na Figura 4b. Se a opção "Finalizar após 5 erros" estiver habilitada, após o quinto erro, o estudante será conduzido à tela mostrada na Figura 4c, caso contrário, o estudante deverá clicar em "Finalizar" para encerrar e ir para a tela seguinte. Na Figura 4c, o estudante tem a sua pontuação detalhada e uma lista com as palavras que errou. Caso tenha alguma dúvida, basta clicar na palavra para acessar as informações da mesma, mostrado na Figura 3c.

$\mathrm{Na}$ opção Dicionário, mostrada na Figura 5c, o estudante pode realizar uma busca rápida por alguma palavra na lista ou digitando a mesma no campo de busca no topo da página, clicando no ícone da lupa. Ao clicar sobre uma palavra específica, ele tem acesso às informações detalhadas, como mostradas na Figura 3c.

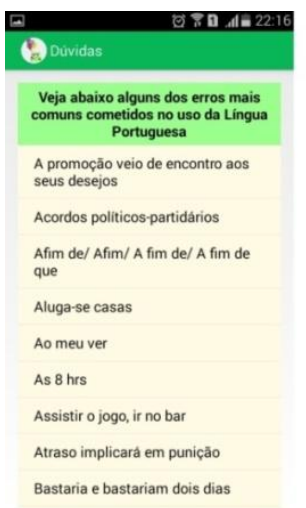

(a)

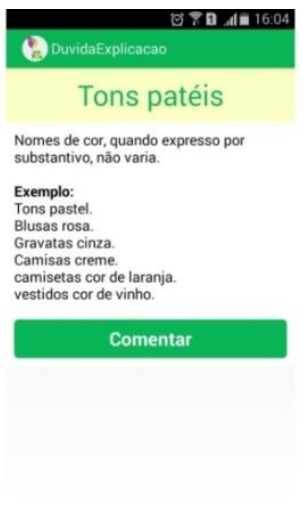

(b)

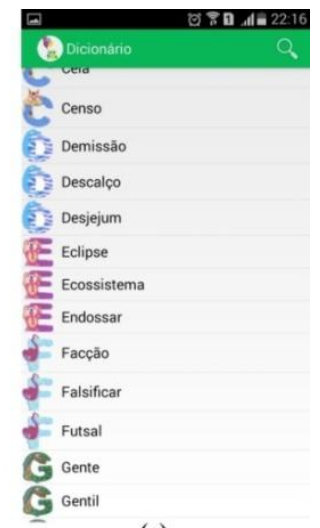

(c)

Figura 5. Dúvidas frequentes e Dicionário 
V Congresso Brasileiro de Informática na Educação (CBIE 2016)

Anais do XXVII Simpósio Brasileiro de Informática na Educação (SBIE 2016)

Uma última funcionalidade pode ser acessada pelo botão com um ponto de interrogação, no canto superior direito da tela principal (Figura 2a). Será apresentada ao estudante a tela da Figura 5a contendo uma lista com erros comuns cometidos no uso da LP. Ao clicar sobre um desses itens, assim como no dicionário, o estudante terá acesso a uma breve explicação sobre o erro e alguns exemplos, como mostrados na Figura $5 b$. Aqui, também é possível inserir um comentário.

\section{Resultados da Inspeção de Usabilidade}

A realização de avaliação e inspeção de usabilidade em sistemas computacionais é primordial para garantir a entrega de um produto mais robusto e de fácil uso. Em aplicações móveis não é diferente, uma vez que uma interface de fácil uso é fundamental para seu sucesso. No entanto, métodos tradicionais de avaliação de usabilidade podem não ser adequados para a avaliação de aplicações móveis [Zhang e Adipat 2005].

Neste caso, duas técnicas foram aplicadas na avaliação deste aplicativo: Userbility, com 25 participantes, é uma técnica utilizada para avaliar a usabilidade em conjunto com a experiência do usuário, e Processo de Guidelines, com 24 participantes, utiliza duas técnicas, uma para inspecionar a usabilidade da aplicação e outra para avaliar a experiência do usuário [Nascimento et al. 2016], totalizando 49 participantes. A seguir é apresentado um resumo com os principais resultados.

A Tabela 2 apresenta um comparativo entre as duas técnicas aplicadas. Foi percebido que, apesar da técnica Userbility demandar mais tempo, a média de defeitos por inspetor foi muito próxima em ambas as técnicas.

Tabela 2. Comparativo entre as técnicas aplicadas

\begin{tabular}{|l|c|c|c|}
\hline & Quant. Inspetores & Tempo Médio (min) & Defeitos por Insp. \\
\hline Userbility & 25 & 59 & 4,64 \\
\hline Processo de Guidelines & 24 & 38 & 4,75 \\
\hline
\end{tabular}

Após a inspeção, foi realizada uma reunião de discriminação, momento em que cada discrepância é classificada como defeito ou falso positivo. Ao final desta, foi contabilizado um total de 106 defeitos reais. É apresentada na Tabela 3 uma amostra destas 106 discrepâncias referenciadas por um identificador único. Informações mais detalhadas referentes às duas técnicas aplicadas e seus resultados podem ser encontradas em [Nascimento et al. 2016].

Tabela 3. Alguns exemplos de discrepâncias encontradas

\begin{tabular}{|c|l|}
\hline Id & \multicolumn{1}{c|}{ Discrepância } \\
\hline 01 & Os ícones da tela principal foram confundidos com imagens, não parecem botões. \\
\hline 02 & Não há botão para voltar à tela anterior, apenas o botão físico do celular. \\
\hline 03 & Tópico de dúvidas identificado pelo símbolo "?" foi confundido com tópico de ajuda. \\
\hline 04 & Ajuda/documentação quase inexistente. \\
\hline 05 & Botões com formatos e cores diferentes. \\
\hline 06 & O termo "Grafo" não é intuitivo. \\
\hline 07 & Ausência de opção para logout e para edição de informação. \\
\hline
\end{tabular}


V Congresso Brasileiro de Informática na Educação (CBIE 2016)

Anais do XXVII Simpósio Brasileiro de Informática na Educação (SBIE 2016)

\begin{tabular}{|c|l|}
\hline 08 & No tópico de dúvidas, não há opção de busca, é necessário fazer uso da barra de rolagem. \\
\hline 09 & A coruja, ícone do aplicativo, não conduz à tela inicial, não é clicável. \\
\hline 10 & Na tela de submissão de dúvidas, os elementos estão desalinhados. \\
\hline
\end{tabular}

Estes resultados evidenciaram a importância de se fazer uma inspeção de usabilidade antes de levar um novo aplicativo para a sala de aula. Erros, falta de padronização, ícones com dupla interpretação ou interpretação incorreta, podem dificultar e desmotivar os estudantes e consequentemente prejudicar justamente o que se deseja melhorar, o processo de aprendizagem.

\section{Conclusão e Trabalhos Futuros}

Este artigo apresentou o aplicativo NaPontaDaLíngua, uma ferramenta gratuita que visa ajudar os estudantes a aperfeiçoarem suas habilidades no uso da LP de forma mais lúdica, trabalhando com a origem das palavras.

A plataforma Android versão 4.0 foi adotada e as informações são armazenadas no SQLite. A internet apenas é necessária ao inserir um comentário, necessitando criar uma conta ou acessar com o Facebook. Os comentários são armazenados em um servidor web com MySql. A implementação foi realizada na IDE Android Studio versão 1.0 e encontra-se disponível em http://napontadalingua2.weebly.com.

A inspeção de usabilidade realizada mostrou-se importante ao revelar muitas discrepâncias, destacando a importância de sua realização antes de proceder com algum experimento real com estudantes. Espera-se melhorar a ferramenta, corrigindo as falhas apontadas e então realizar experimentos em escolas com o apoio de professores de língua portuguesa.

Há também uma lista de recursos a serem melhorados ou implementados em versões futuras como, por exemplo, permitir que o professor insira exercícios para os alunos, aproveitando os recursos e a base de dados da ferramenta, tornando-a assim mais interativa.

Outro aspecto a ser trabalhado é a interação entre os próprios estudantes, permitindo desafios, ranking com a pontuação do jogo e mesmo classificações por tempo, como por exemplo, o melhor do mês.

Por fim, também seria interessante melhorar o recurso de comentários, implementando notificações, para que o estudante possa escolher ser notificado sempre que alguém inserir um novo comentário em uma palavra que ele também comentou, facilitando assim a visualização de possíveis respostas a uma dúvida postada.

\section{Agradecimentos}

Os autores agradecem o apoio do "Programa de Qualificação em Grande Escala em Tecnologias Móveis - PROMOBILE", projeto patrocinado pela Samsung Eletrônica da Amazônia Ltda. nos termos da lei federal brasileira $n^{\circ}$ 8.248/91.

\section{Referências}

Alves, R. S.; Araujo, J. O. A. e Madeiro, F. (2012) "AlfabetoKinect: Um aplicativo para auxiliar na alfabetização de crianças com o uso do Kinect", Simpósio Brasileiro de Informática na Educação (SBIE). 
V Congresso Brasileiro de Informática na Educação (CBIE 2016)

Anais do XXVII Simpósio Brasileiro de Informática na Educação (SBIE 2016)

Gaspar, W.; Oliveira, E. H. T e Oliveira, K. M. T. (2015) "Aprendizagem da Língua Portuguesa com Dispositivos Móveis: Um Mapeamento Sistemático da Literatura", Simpósio Brasileiro de Informática na Educação (SBIE).

Kitchenham, B. A.; Budgen, D. e Brereton, O. P. (2011) "Using mapping studies as the basis for further research - A participant-observer case study", Information and Software Technology, Volume 53, Edição 6, Jun.

Lopes, J. G. (2014) "Protótipo de Material Didático Interativo para Ensino de Língua Portuguesa”, EmRede - Revista de Educação a Distância v.1, n.1.

Luz, J. W. P. e Fonseca, L. C. C. (2013) "EduConnect: uma ferramenta de apoio à aprendizagem colaborativa para dispositivos móveis em redes MANET", Simpósio Brasileiro de Informática na Educação (SBIE).

Marques, D. L. e Silva, A. P. S. (2012) "OrtograFixe - Um jogo para apoiar o ensinoaprendizagem das regras da nova reforma ortográfica", Simpósio Brasileiro de Informática na Educação (SBIE).

Nascimento, I.; Silva, W.; Lopes, A.; Rivero, L.; Gadelha, B.; Oliveira, E.; Conte, T. (2016) "An Empirical Study to Evaluate the Feasibility of a UX and Usability Inspection Technique for Mobile Applications", 28th International Conference on Software Engineering \& Knowledge Engineering, California, USA.

Paschoal, L.; Bento, T.; Velasco, T.; Schocair, C. O.; Castaneda, R.; Oliveira, T. e Ogasawara, E. (2014) “JOE: Jogo Ortográfico Educacional”, Simpósio Brasileiro de Informática na Educação (SBIE).

Petersen, K.; Feldt, R.; Mujtaba, S. e Mattsson, M. (2008) "Systematic mapping studies in software engineering", "Proceedings of the 12th international conference on Evaluation and Assessment in Software Engineering" (EASE'08), Giuseppe Visaggio, Maria Teresa Baldassarre, Steve Linkman, and Mark Turner (Eds.). British Computer Society, Swinton, UK, UK, 68-77.

Romanelli, B. M. B. e Guimarães, S. R. K. (2009) "Ortografia do português do Brasil e habilidades linguísticas em crianças bilíngues francês-português", Psicologia em Pesquisa | UFJF | 3(01) | 101-114 | janeiro-junho.

Santos, M. J.; Rosa, M. N. S. D. e Nicolau, A. P. (2009) "Ortografia: Aprendizagem e Ensino", Poiésis Pedagógica - v. 7 - p. 109-129 - jan./dez.

Silva, A. R. S.; Façanha, A. R.; Viana, W.; Filho, J. A. C. e Sánchez, J. (2014) "Especificação e desenvolvimento de um ambiente educativo móvel para a prática da escrita Braille", Simpósio Brasileiro de Informática na Educação (SBIE).

Tavares, J. E. R.; Leithardt, V.; Geyer, C. F. R. e Silva, J. S. (2014) "Uma aplicação para o ensino da língua portuguesa para surdos utilizando o SensorLibras", Simpósio Brasileiro de Informática na Educação (SBIE).

Zanella, M. S. (2010) "Ortografia no Ensino Fundamental: Um Estudo Sobre as Dificuldades no Processo de Aprendizagem da Escrita”, Poíesis Pedagógica - v.8, N.2 - p.109-125- ago/dez.

Zhang, D. e Adipat, B. (2005) "Challenges, methodologies, and issues in the usability testing of mobile applications", International Journal of Human-Computer Interaction, vol. 18, n. 3, pp. 293-308. 